\title{
Data-based decision making in developing countries: Balancing accountability measures and improvement efforts
}

\author{
Kim Schildkamp, Cindy L. Poortman, \& Pasi Sahlberg
}

Research has shown that data use can lead to increased student achievement (Carlson et al., 2011; Lai, et al., 2009; Poortman and Schildkamp, 2016; Van Geel et al., 2016). At the same time, more and more data have become available to schools and teachers. Education authorities are increasingly expected to make use of data (e.g., national assessment data, international large-scale assessments) in decision-making regarding education policy and reforms. School leaders and teachers have more data available from classrooms and schools through observations and surveys that they can take into account in individual and collective professional judgment regarding teaching. This is often referred to as data-based decision making, data use for short. This involves the systematic collection, analysis, and interpretation of multiple data sources, such as assessment results and classroom observations, to improve education (Schildkamp and Kuiper, 2010).

Data use is not only important from the perspective of student achievement, but also from an equity perspective. We know from research that students from disadvantaged family backgrounds are more likely to be placed in (specific) lower educational tracks or disadvantaged schools (Bertrand and Marsh, 2015; Marks et al., 2006; OECD 2018). One of the reasons for this is what is called confirmation bias: Once teachers have a hypothesis about pupils' competencies, they tend stick with this assumption (Harteis, et al., 2008; Kahneman and Frederick, 2005). Reliable data use can help to challenge these assumptions and can be used as a more objective tool in the school improvement process (Vanlommel and Schildkamp, 2018). Better comparable data can also help formulate stronger policy arguments to change the course of school policies that have led to social segregation of children in schools based on their socio-economic status. Indeed, some studies have shown that data use can increase equity, i.e., reduce the achievement gap between indigenous students and non-indigenous students (Care et al., 2014; Bol et al., 2014; Lai \& McNaughton, 2018; Park et al., 2017). Data use can help schools and school systems towards higher quality provision, especially for marginalized communities (Rosenkvist, 2010; Wagner et al., 2012).

Of course, the presence of data does not guarantee implementation of better policies or practices, but its absence often leads to problems or failure. Data use can be a powerful tool in the school improvement process. With today's technological tools, more and more data are available and/or accessible, which can provide timely updates on the quality of education for different stakeholders. Data can provide different stakeholders with information on achievement from different sources and with information on the learning needs of students, which can be used to improve education for all students.

We must also be mindful of the possible pitfalls of data use, however. It is not always easy for educators to use data. Sometimes, often due to policy pressure, data use becomes a goal in itself, rather than a tool in the school improvement process. Moreover, educators often have a 
lack of knowledge and skills (i.e., data literacy) to make effective use of data (Mandinach and Gummer, 2013; Schildkamp and Kuiper, 2010; Kippers, Poortman, Schildkamp, and Visscher, 2018). Data overflow can also become an obstacle to mindful data-based decision-making and practice: In some developed countries the challenge is not about lack of accurate and useful information anymore, but rather about having too much data. Finally, there is a risk of misuse of data, for example if the focus is solely on standardized assessment data, and if efforts are (mostly) focused on students just below a certain threshold (Ehren and Swanborn, 2012; Hamilton et al., 2009).

Several studies into data use have been conducted in countries all over the world, for example in the United States (Datnow et al., 2013), Belgium (Van Gasse et al., 2016), New Zealand (Lai et al., 2009), Norway (Mausethagen et al., 2018), and The Netherlands (Schildkamp and Kuiper, 2010). Little is known, however, about data use in developing countries. Education management information systems (EMIS) that are designs of various data collection and analysis mechanisms have typically become mainstream elements in developing countries through their engagement with international development agencies and bilateral donors. Many of these countries are struggling with (large) education and public sector reforms as well as the tensions between accountability and school improvement. Between 1998 and 2014 the World Bank invested in development of over 200 EMIS-related education projects around the developing world that accounts for about half of all the Bank's projects. The common goal of these efforts has been to improve education through better data for authorities and practitioners. A recent review (Abdul-Hamid et al., 2017) of these data systems as part of education sector development indicated that, together with obvious benefits, developing countries often suffered from misalignment of data handling activities, institutionalizing of these information systems, and lack of capacity to maintain data use reliable and trustworthy.

There is a need to study data use in developing countries, because this may contribute to solving problems such as a lack of good infrastructure and qualified teachers, in addition to directly supporting student learning (UNESCO, 2013). Furthermore, education management information systems and data use more specifically often raise questions about integrity and good governance of data in developing countries that has been an ongoing area of research during the past two decades (Transparency International, 2013).

This special issue focuses on both the promises and pitfalls of data use in the context of schools in developing countries.

The first article (Eddy-Spicer et al., 2019) presents the results of a systematic literature review of the conditions and mechanisms through which performance monitoring in low- and middleincome countries improves school-level outcomes. The review uses the methodology of realist synthesis and identifies papers focused on monitoring from Sub-Saharan Africa, Latin America, and East and South Asia. The review highlights key barriers to the use of data to inform school accountability and improvement, focusing on an array of monitoring activities that involve the use of data, including Educational Management and Information Systems (EMIS), school report 
cards, and local school development planning (SDP). Their analysis reveals the essential interconnections among mechanisms, such as providing feedback; conditions, such as followup/follow through; and outcomes, such as improvement in instructional management processes. The findings suggest that educators' capacity development is a crucial condition for effective monitoring. Through its application of realist synthesis to educational literature, the review also contributes to the methodological toolkit for conducting systematic reviews in education.

The second paper focuses on the use of data in Indonesia (Abdusyakur and Poortman, 2019). Despite an increased emphasis on a decentralized education system in Indonesia over the past ten years, more effort is still needed in building up school-level capacity to manage better education services and in ensuring government-level sufficient support and control. There is also a need for more appropriate use of the assessment of student learning in achieving better student performances in the future. The results of this mixed-methods study show that Indonesian primary schools have a lot of data available, similar to the data available in developed countries. However, the results also show that educators had difficulties in accessing data, because of unreliable information systems. Furthermore, the focus seems to be mostly on the use of one type of data (e.g., examination results) for accountability. Data were often simply collected to comply with regulations, often not shared, and sometimes used to teach to the test, instead of used for actual improvement of teaching and learning in the school. This type of behavior was heavily influenced by policy, as heads of schools had to deliver monthly reports to the government, and teachers had to submit several types of data as a requirement for receiving monthly allowances. The results of the study also show that there is a lack of collaboration around the use of data in some schools, and that the school leaders are sometimes too demanding and not supportive. Teachers and heads of schools also appear to lack data literacy skills, indicating that professional development and training in the use of data is urgently needed.

The third study was conducted in Kenia (Omoso et al., 2019). This paper employed a multiple case study design to explore data availability, use, together with the factors that promote or hinder its use in Kenyan secondary schools. The results show that although different types of input, process, output, and context data are available, the focus is mostly on student achievement data. Moreover, the results also reveal a limited use of data on the part of teachers and school leaders. Head teachers mainly use school-level data to monitor, plan and develop policies which emphasize school and curriculum development (e.g., starting pupil feeding program), but they focus less on teacher development, for example. Moreover, an indepth analysis of data seem to be missing, and decisions are based on a shallow analysis of one type of data. For example, lower achievement scores in certain subjects (compared to other subjects) led to additional classes on Saturday for these subjects, without examining what caused lower achievement. Teachers mainly use classroom level data to plan their lessons and monitor students' progress. The focus is mostly on syllabus coverage, and sometimes reteaching based on low student achievement data. Most teachers do not use data to improve their instruction in the classroom. Data were mostly used for internal (from head teachers to 
teachers) and external (from head teachers to inspectors) accountability, with a focus on judging and comparing schools and teachers based on test scores. A lack of data use in Kenya is likely the result of a lack of data literacy, a lack of professional development and training in the use of data, and a lack of access to technology that can support data collection, storage, analysis and access to data.

The fourth study was conducted in Ethiopia (Yibrie, 2019). Based on a conceptual framework that captures the different types of data, data use purposes, and promoting and hindering factors, the study aimed to investigate how schools use data in the context of school improvement. The study employed an exploratory mixed-methods research design. The findings of this study indicate that both high and low performing schools had a wide range of input, process, context, and output data available. Certain kinds of data (e.g. socio-economic status) were only found in some high performing schools. Educators used data for accountability, school development and instructional improvement. In several schools in this study the focus was mainly on data use for accountability (i.e., teacher performance evaluation and reporting to school governing bodies). There were even examples of accountability pressure experienced as very high: to the extent that teachers inflated student test scores and comprised the authenticity of reported achievement scores in teacher made tests. However, there were also some examples of data use for instructional improvement, for example in terms of using data to enhance students' self-directed learning and using data to differentiate instruction. Most examples of data use for instruction were limited to grouping students based on their achievement results and then providing tutorials for low achievers, however. Several factors were found to hinder the use of data, including a lack of access to high quality data, high workload, and a negative attitude (i.e., data use as an additional responsibility).

When comparing the results of these studies to the results of data use studies conducted in other countries it seems that similar data sources are available in the different schools, including input data, process data, output data, and context data (Abdusyakur and Poortman, 2019; Omoso et al., 2019; Yibrie, 2019). However, different types of data are also available, such as data on the distance that students have to walk to school, data on whether or not the students have been fed before going to school, and data on the home situation of the students. Educators, both policy-makers and teachers, in developing countries seem to struggle with using data for school and instructional improvement as well as in other countries. The focus seems to be mostly on data use for accountability (Abdusyakur and Poortman, 2019; Omoso et al., 2019; Spicer et al., 2019; Yibrie, 2019), and mostly accountability towards some governing body and not so much towards parents. Parents are important stakeholders in the process of data use for school improvement; they can exert pressure on schools to improve, and they can participate in monitoring activities. These participatory approaches can lead to the actual use of data to improve education, and they can lead to reductions in pupil and teacher absenteeism in schools, and increased student achievement (Spicer et al., 2019). This was not generally found in the studies conducted in Indonesia, Kenia, and Ethiopia. In some examples, however, educators managed to use data not only to improve the education of their students, but also the quality of their students' lives. For example, in some schools in Kenia, data were used for setting up support programs for single parent mothers of students with discipline and 
achievement problems, and data were used to determine which students are eligible for free breakfast (Omoso et al., 2019).

When it comes to the enabling and hindering factors of data use, the same factors as found in many other countries were important here. A review on the factors influencing the use of data for school improvement (Hoogland et al., 2016) shows that it is important to use multiple data sources to prevent bias and that these data are accessible. Several educators in the studies in this special issue complained about a lack of access to high quality data (Abdusyakur and Poortman, 2019; Omoso et al., 2019; Yibrie, 2019). The review by Hoogland et al. stresses the importance of collaboration and a data use culture (e.g., vision, norms, goals). A lack of collaboration was found to be a hindering factor in several of the studies reported here (Abdusyakur and Poortman, 2019; Omoso et al., 2019; Yibrie, 2019).

Data literacy is a crucial requirement as well as access to professional development and training (Hoogland et al., 2016). Inadequate data literacy among policy-makers and practitioners combined with lack of access to training and professional development were found to be barriers in several of the studies in this special issue (Abdusyakur and Poortman, 2019; Omoso et al., 2019; Spicer et al., 2019; Yibrie, 2019). Collaboration is important between teachers and school leaders, who are all professionals in the sense of being open, rigorous, challenging, and data-informed (Hargreaves et al., 2018). By bridging collaboration and professionalism in schools by forming professional learning communities, this forms a perfect setting for what Datnow and Park (2019) call professional collaboration with purpose (Datnow and Park, 2019).

In the discussion paper (Voogt and Pieters, 2019) the findings addressed by the other articles are integrated. Voogt and Pieters discuss their insights from the perspective of system characteristics and culture. They also discuss opportunities for data use in developing countries given decentralization efforts, specifically related to increasing the power of clients (community power); capacity building; and the need for both horizontal and vertical accountability.

The papers in this special issue show what types of data and data use, and influencing factors, are different and similar in the developing country context compared to the contexts in which studies so far have been conducted. While the structural changes implemented in the contexts addressed in this issue are meant to promote access and equity, the balance between improvement efforts and accountability measures is a struggle, indicating the need to develop professional capital in schools, but also alignment between policy assumptions and school and classroom conditions (Yibrie, 2019; Spicer et al., 2019).

\section{References}

Abdul-Hamid, H., Saraogi, N., and Mintz, S. (2017). Lessons Learned from World Bank Education Management Information System Operations: Portfolio Review, 1998-2014. World Bank Studies;. Washington, DC: World Bank. 
Carlson, D., Borman, G. D., and Robinson, M. (2011). “A Multistate District-Level Cluster Randomized Trial of the Impact of Data-Driven Reform on Reading and Mathematics Achievement", Educational Evaluation and Policy Analysis, 33, 378-398.

Datnow, A. and Park, V. (2019). Professional collaboration with purpose: Teacher learning for equitable and excellent schools. New York: Routledge.

Datnow, A., Park, V., and Kennedy-Lewis, B. (2013). "Affordances and constraints in the context of teacher collaboration for the purpose of data use", Journal of Educational Administration, 51(3), 341-362.

Hargreaves, A., Shirley, D., Wangia, S., Bacon, C., and D'Angelo, M. (2018). Leading from the middle: Spreading learning, well-being, and identity across Ontario. Toronto, Canada: Council of Ontario Directors of Education.

Kippers, W. B., Poortman, C. L., Schildkamp, K., and Visscher, A. J. (2018). "Data literacy: What do educators learn and struggle with during a data use intervention?", Studies in educational evaluation, 56, 21-31.

Lai, M.K. and McNaughton, S. (2018). "Learning networks for sustainable literacy achievement", Brown, C. and Poortman, C.L. (Eds.) Networks for Learning (pp. 152-171). London: Routledge.

Lai, M. K., McNaughton, S., Timperley, H., and Hsiao, S. (2009). "Sustaining continued acceleration in reading comprehension achievement following an intervention", Educational Assessment, Evaluation and Accountability, 21, 81-100.

Mausethagen, S., Prøitz, T., and Skedsmo, G. (2018). "Teachers' use of knowledge sources in 'result meetings': thin data and thick data use, Teachers and Teaching", 24(1), 37-49.

Poortman, C.L., and Schildkamp, K. (2016). "Solving student achievement focused problems with a data use intervention for teachers", Teaching and Teacher Education, 60, 425433.

Schildkamp, K., and Kuiper, W. (2010). “Data-informed curriculum reform: Which data, what purposes, and promoting and hindering factors", Teaching and Teacher Education, 26(3), 482-496.

Schildkamp, K., Poortman, C.L., Luyten, J.W., and Ebbeler, J. (2016). “Factors promoting and hindering data-based decision making in schools", School Effectiveness and School Improvement, 1-17.

Transparency International (2013). The Global Corruption report: Education. London: Routledge. Van Geel, M., Keuning, T., Visscher, A. J., and Fox, J. P. (2016). "Assessing the effects of a schoolwide data-based decision-making intervention on student achievement growth in primary schools", American Educational Research Journal, 53(2), 360-394. 
Van Gasse, R., Vanlommel, K., Vanhoof, J. and Van Petegem, P. (2016). "Teacher collaboration on the use of pupil learning outcome data: A rich environment for professional learning?", Teaching and Teacher Education, 60, 387-397.

UNESCO, T. (2013). Learning: Achieving quality for all. The EFA global monitoring report, Paris http://unesco. nl/sites/default/files/dossier/gmr_2013-4. pdf. Retrieved March 20, 2019. 